\title{
Numerical Simulation of the Gas-Liquid Flow inside a Horizontal Static Mixer
}

\author{
Ryan Anugrah Putra a,1,*, Akhlisa Nadiantya Aji Nugroho ${ }^{\mathrm{a}, 2}$ \\ ${ }^{a}$ Department of Mechanical \& Industrial Engineering, Faculty of Engineering, Universitas Gadjah Mada, \\ Jalan Grafika No. 2, 55281 Yogyakarta, Indonesia \\ Iryan.putra@ugm.ac.id*; ${ }^{2}$ akhlisa.nadiantya.a@mail.ugm.ac.id \\ * corresponding author
}

The gas-liquid flow inside a horizontal static mixer was numerically Accepted investigated by using Euler-Euler Computational Fluid Dynamics (CFD) simulations. The results confirm that the liquid superficial velocity plays a significant role in the mixing behavior of the gas and liquid. The mixing behavior in this present study at a liquid superficial velocity of $0.2 \mathrm{~m} / \mathrm{s}$ was the worst both axially and radially. Increasing

Keywords:

Static mixer

CFD

Gas-liquid

Rotating flow the liquid superficial velocity significant improves the mixing between gas and liquid. However, the unwanted gas layer can still be found at the superficial liquid velocity of less than $0.8 \mathrm{~m} / \mathrm{s}$. A good mixing behavior in this study was achieved at a relatively high velocity (i.e., larger than $0.8 \mathrm{~m} / \mathrm{s}$ ).

Copyright $(C 2020$ Politeknik Aceh Selatan. All rights reserved.

\section{Introduction}

Rotating flow can be found in nature, such as ocean whirlpool [1], tropical cyclones and tornadoes [2] as well as in many engineering applications such as heat transfer [3], combustion [4], phase separation and mixing [5], [6]. In the case of gas-liquid flow, a static swirl element can be used inside a pipe to generate the rotating flow responsible either for mixing or separating the gas and liquid phases [6], [7]. In contrast to a single-phase flow, the gas-liquid flow inside a static mixer is a complex phenomenon [8]. More studies, both experimental and numerical, are still required to achieve a great understanding and optimize the process [8], [9].

An experimental study on the gas-liquid flow inside a vertical static mixer using $\mathrm{x}$-ray tomography was conducted by [6]. They reported that the radial gas profile at low superficial liquid velocity (i.e., $0.2 \mathrm{~m} / \mathrm{s}$ ) is more well-distributed than the one at high superficial liquid velocity (i.e., $0.6 \mathrm{~m} / \mathrm{s}$ ) for the same gas superficial velocity (e.g., $0.23 \mathrm{~m} / \mathrm{s}$ ) [6]. Next, an experimental study on the gas-liquid flow inside the vertical pipe equipped with the blade type swirl element was carried out by [8]. They presented the radial gas distribution profiles obtained from the measurement using gamma-ray tomography, which confirmed the complexity of the gas-liquid flow inside the swirl generating device [8]. The computational fluid dynamics (CFD) simulations using the Euler-Euler approach based on the experiment of [6] and [8] were performed by [9] and [8], respectively. A numerical study to compare the gas-liquid flow characteristics for a different type of static swirl elements (i.e., the blade type, the single helix, and the double helix swirl elements) using CFD was performed by [7]. A numerical investigation by [10] demonstrated that the gas distribution inside the vertical static mixer is also influenced by the length to diameter ratio of the static swirl. They showed the gas distribution profile is significantly different between those elements [10]. Those previous works describe the complexity of the flow, which can be affected by several factors, including the phase flow rate and the geometry of the swirl element. It is also important to note that those works were performed for the vertical pipe. In the case of horizontal pipe equipped with swirl elements, the previous works available in the literature mostly deal with the separation between gas and liquid e.g., in [11]. Therefore, in this work, the numerical study was conducted to investigate the gas-liquid flow characteristic inside the horizontal static mixer. 


\section{Method}

Fig.1a shows the computational domain used in the present study, which is composed of a horizontal pipe having a diameter of $27 \mathrm{~mm}$ and a length of $500 \mathrm{~mm}$. The static mixer element (see Fig. 1b) having a length of $50 \mathrm{~mm}$ and a diameter of $27 \mathrm{~mm}(\mathrm{~L} / \mathrm{D}=1.9)$ is located at an axial distance of $100 \mathrm{~mm}$ from the inlet. Investigate the mixing behavior, the gas distribution at several planes (i.e., P1-P6 in Fig. 1a) located at some distance in the domain, as listed in Table 1, were evaluated.

(a)

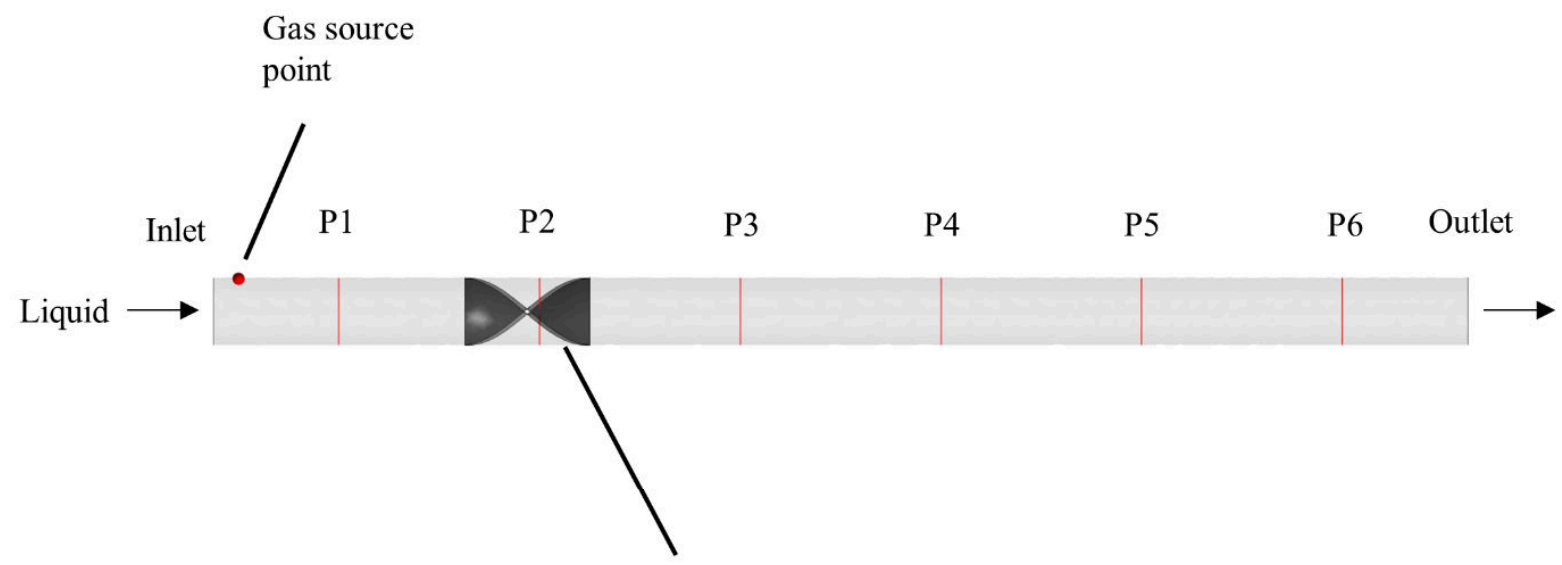

(b)

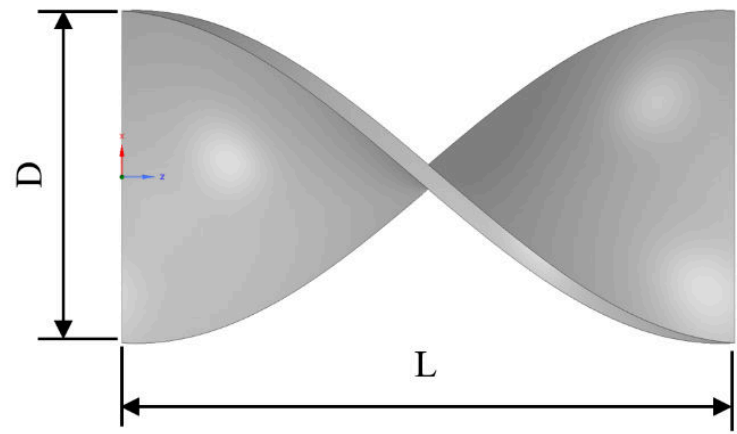

Fig. 1.(a) CFD domain (b) the static mixer element. The images are adapted from [10].

Table 1. Distance relative to the inlet (see Fig. 1a)

\begin{tabular}{cc}
\hline Position & Distance $(\mathbf{m m})$ \\
\hline Inlet & 0 \\
\hline P1 & 50 \\
\hline P2 & 130 \\
\hline P3 & 210 \\
\hline P4 & 290 \\
\hline P5 & 370 \\
\hline P6 & 450 \\
\hline Outlet & 500
\end{tabular}

The Euler-Euler model using fixed computational cells in which two sets of continuity and momentum equations (i.e., each set for liquid and gas phases) are solved selected in this study. The liquid (i.e., water) was defined as the continuous phase, while uniform air bubbles having a diameter of $0.5 \mathrm{~mm}$ were defined as the dispersed gas phase. The continuity and momentum equations are given in (1) and (2), respectively [12]:

$$
\frac{\partial}{\partial t}\left(\alpha_{j} \rho_{j}\right)+\nabla \cdot\left(\alpha_{j} \rho_{j} \boldsymbol{u}_{j}\right)=S_{j}
$$




$$
\frac{\partial}{\partial t}\left(\alpha_{j} \rho_{j} \boldsymbol{u}_{j}\right)+\nabla \cdot\left(\alpha_{j}\left(\rho_{\alpha} \boldsymbol{u}_{j} \times \boldsymbol{u}_{j}\right)\right)=-\alpha_{j} \nabla p+\nabla \cdot\left(\alpha_{j} \mu_{j}\left(\nabla \boldsymbol{u}_{j}+\left(\nabla \boldsymbol{u}_{j}\right)^{T}\right)\right)+\boldsymbol{M}_{j}+S_{M j}
$$

The volume fraction, the density, and the velocity vector of phase $j$ are represented by $\alpha_{j}, \rho_{j}$, and $\boldsymbol{u}_{j}$, respectively [12]. The variables $t, S_{j}$, and $p$ in the above equations are the time, mass source, and pressure, respectively [12]. The variable $S_{M j}$ represents the momentum sources due to external body forces, while $\boldsymbol{M}_{j}$ represents the sum of the bubble forces [12]:

$$
\boldsymbol{M}_{j}=\boldsymbol{F}_{\text {drag }}+\boldsymbol{F}_{\text {lift }}+\boldsymbol{F}_{\text {wall }}+\boldsymbol{F}_{T D}+\boldsymbol{F}_{V M}
$$

In the present study, the bubble forces which are composed of drag force $\boldsymbol{F}_{\text {drag }}$, lift force $\boldsymbol{F}_{\text {lift }}$, wall lubrication force $\boldsymbol{F}_{\text {wall }}$, turbulent dispersion force $\boldsymbol{F}_{T D}$, and virtual mass force $\boldsymbol{F}_{V M}$ were defined based on some selected models listed in Table 1. The k- $\omega$-based shear stress transport (SST) model proposed by [13] was selected as the turbulence model for the continuous phase. The account for the influence of bubble induced turbulence, the model of [14], was used in this work.

Table 2. Selected bubble force models

\begin{tabular}{cc}
\hline Forces & Models \\
\hline Drag force $\boldsymbol{F}_{\text {drag }}$ & {$[15]$} \\
\hline Lift force $\boldsymbol{F}_{\text {lift }}$ & {$[16]$} \\
\hline Wall lubrication force $\boldsymbol{F}_{\text {wall }}$ & {$[17]$} \\
\hline Turbulent dispersion force $\boldsymbol{F}_{T D}$ & {$[18]$} \\
\hline Virtual mass force $\boldsymbol{F}_{V M}$ & {$[19]-[21]$} \\
\hline
\end{tabular}

Investigate the influence of the superficial liquid velocity on the mixing behavior inside the static mixer, the superficial liquid velocity in the range of $J_{L}=0.2-1.0 \mathrm{~m} / \mathrm{s}$ was defined as the boundary condition at the inlet. The superficial gas velocity was kept constant at $J_{G}=2 \times 10^{-3} \mathrm{~m} / \mathrm{s}$ and was introduced into the liquid flow by using a source point (see Fig. 1a) at the axial distance of $20 \mathrm{~mm}$ from the inlet. The boundary at the outlet was a pressure boundary. All other parts were defined as a wall where the no-slip wall and the free-slip wall conditions were defined for the liquid and gas phase, respectively. A commercial software ANSYS CFX 19.2 Student Edition was used for the CFD simulations under the steady-state and adiabatic mode.

\section{Results and Discussion}

Fig. 2 shows the contour of gas volume fraction plotted on the central axial plane for different liquid superficial velocities. For all conditions, the injected gas in the region upstream of the static mixer element only flows in the upper part of the pipe. For the smallest liquid superficial velocity tested in this study (i.e., $J_{L}=0.2 \mathrm{~m} / \mathrm{s}$ ), the axial mixing or contacting between liquid and gas was the worst. The significant mixing was only observed in the static mixer element region. Downstream the element, the gas flows again toward the upper part of the pipe due to the buoyancy and remains at that location until the outlet. Increasing the liquid superficial velocity to $J_{L}=0.3 \mathrm{~m} / \mathrm{s}$ leads to a significant improvement in the axial mixing behavior downstream of the element. However, the mixing process only limited at certain axial distances downstream of the element. At a certain distance, the gas again flows toward the upper part of the pipe and remains there until the outlet. The mixing behavior further improved by increasing the liquid superficial velocity to $J_{L}=0.4 \mathrm{~m} / \mathrm{s}$. The gas accumulation indicated with red contour at $J_{L}=0.3 \mathrm{~m} / \mathrm{s}$ was reduced by the increase of the velocity. In contrast to the mixing at $J_{L}=0.3 \mathrm{~m} / \mathrm{s}$, the gas spread more uniform until the outlet. However, a thin layer of gas at the upper part of the pipe can still be observed from the contour plot.

Further increasing the liquid superficial velocity leads to a more uniform mixing. The thin gas layer in the upper part of the pipe gradually disappears with the increase of the velocity. The observed mixing behavior closely related to the flow condition downstream of the element shown in Fig. 2. In the case of $J_{L}=0.2 \mathrm{~m} / \mathrm{s}$, the swirling flow was only generated effectively, very close to the element. After a certain distance, the swirling flow was decayed, which is indicated by the change in the streamlines from the helical to the straighter streamlines. Increasing the liquid superficial velocity to 
$J_{L}=0.3 \mathrm{~m} / \mathrm{s}$ leads to a delay in the decay of the swirling flow; thus, it occurs at a distance longer than in $J_{L}=0.2 \mathrm{~m} / \mathrm{s}$.

The rotational strength seems not strong enough to maintain the swirling flows until the outlet. Therefore, the gas phase is no longer able to be held around the center of the pipe; thus, it migrates toward the upper part of the pipe. The increasing again, the liquid superficial velocity leads to a more sustained swirling flow. For example, the streamlines at $J_{L}=1.0 \mathrm{~m} / \mathrm{s}$ show a much more intense helical pattern in comparison to the streamlines at $J_{L}=0.3 \mathrm{~m} / \mathrm{s}$.

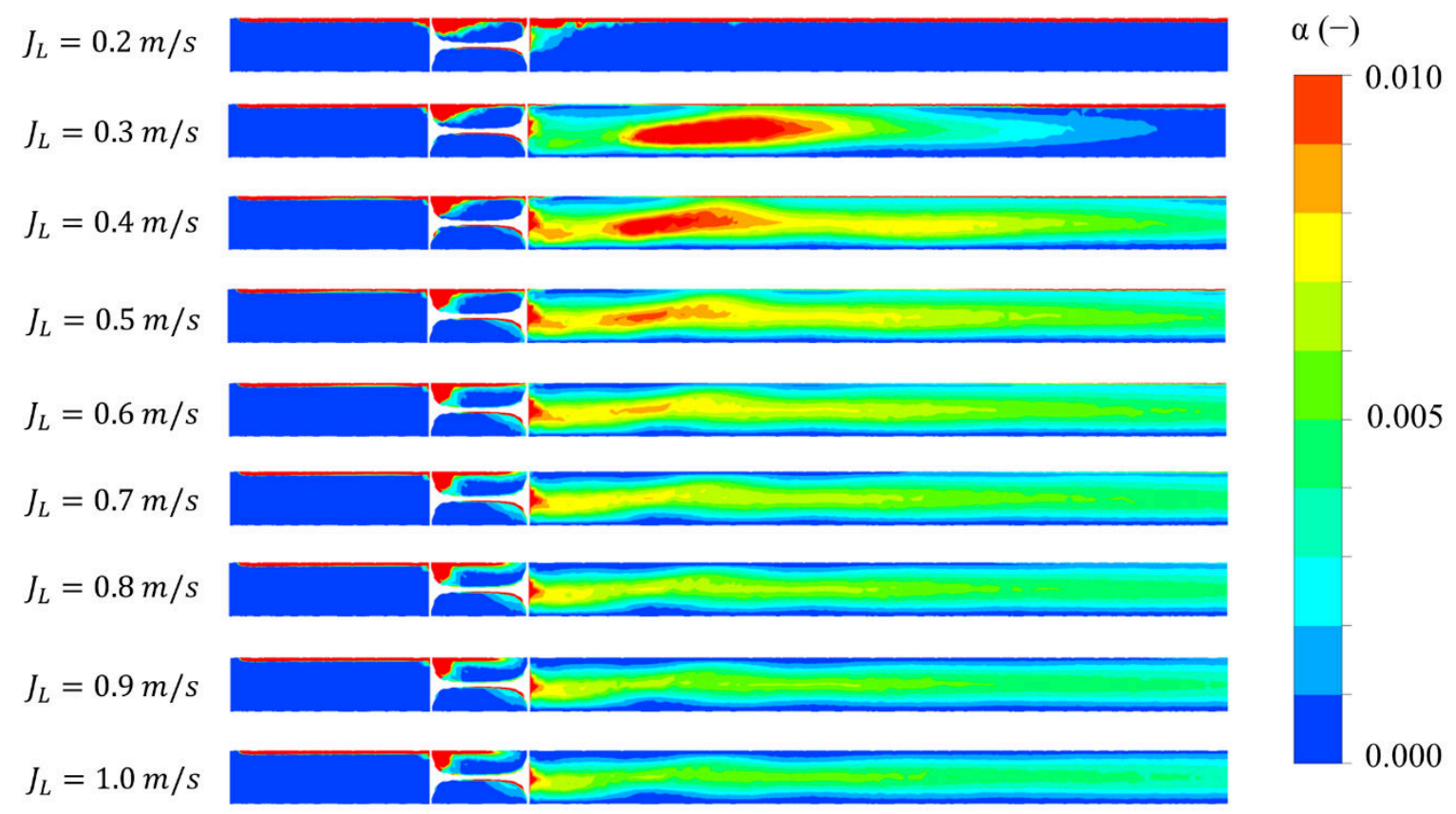

Fig. 2. Contour plot of gas volume fraction on the central axial plane for different liquid superficial velocities.

$$
\begin{aligned}
& J_{L}=0.2 \mathrm{~m} / \mathrm{s} \\
& J_{L}=0.3 \mathrm{~m} / \mathrm{s} \\
& J_{L}=0.4 \mathrm{~m} / \mathrm{s} \\
& J_{L}=0.5 \mathrm{~m} / \mathrm{s} \\
& J_{L}=0.6 \mathrm{~m} / \mathrm{s} \\
& J_{L}=0.7 \mathrm{~m} / \mathrm{s} \\
& J_{L}=0.8 \mathrm{~m} / \mathrm{s} \\
& J_{L}=0.9 \mathrm{~m} / \mathrm{s} \\
& J_{L}=1.0 \mathrm{~m} / \mathrm{s}
\end{aligned}
$$
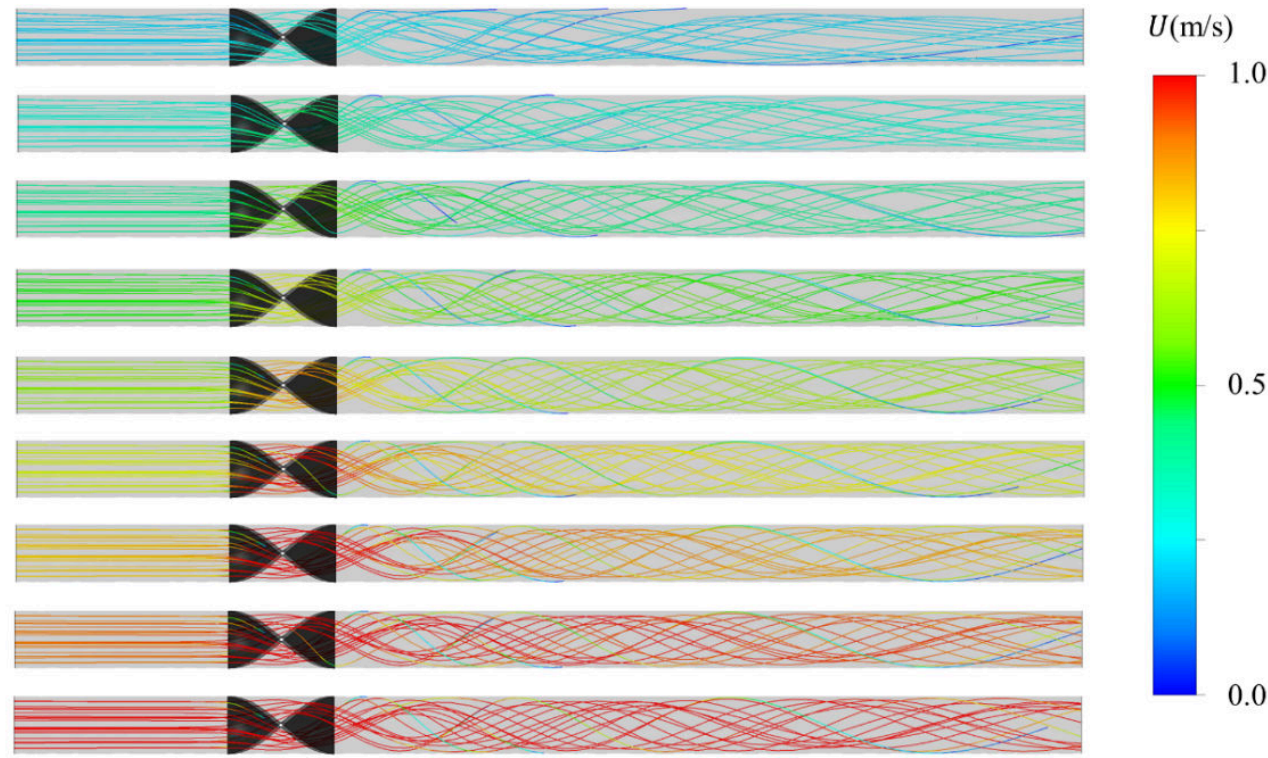

Fig. 3.Example of a figure caption.

The contour of gas distribution on several cross-sectional planes is shown in Fig.4. The contour at P1, which is located upstream, the static mixer element confirms that the gas is accumulated at the upper part of the pipe for all tested conditions. The gas is started to have more contact with water in the static mixer element region, as shown in P2. For the case of $J_{L}=0.2 \mathrm{~m} / \mathrm{s}$ (see Fig. 4a), the gas at P3 to P6 has the worst mixing condition as 
it remains in the same position (i.e., at the upper part of the pipe). For the case of $J_{L}=0.3 \mathrm{~m} / \mathrm{s}$ (see Fig. $4 \mathrm{~b}$ ), the gas downward the element is more distributed in comparison to the one in $J_{L}=0.2 \mathrm{~m} / \mathrm{s}$. However, the accumulation of the gas in the upper part of the pipe can still be clearly observed at P4 to P6. The radial gas distribution downward the element was further improved by increasing the liquid superficial velocity. In the case of $J_{L}=0.6 \mathrm{~m} / \mathrm{s}$, although the gas layer near the upper part of the pipe at P6 is still present, it is gradually disappearing at P4 and P5 is gradually disappeared (see Fig. 4e). For the relatively high superficial velocity (e.g., $J_{L}=1 \mathrm{~m} / \mathrm{s}$ ) the gas layer accumulation near the upper part is no longer present (see Fig. $4 \mathrm{i}$ ). The mixing process is already largely improved in this condition.

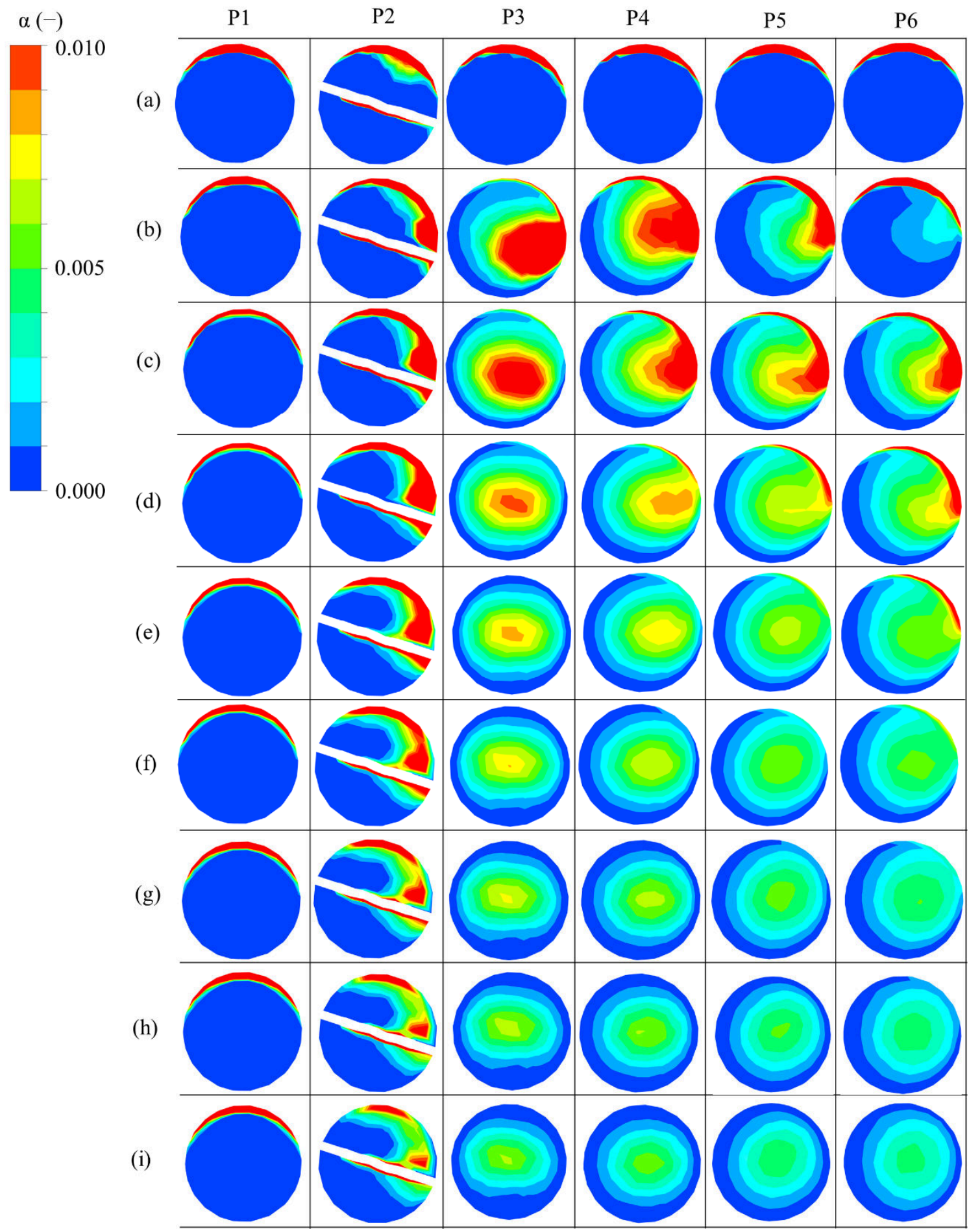

Fig. 4. Example of a figure caption. (figure caption) 


\section{Conclusion}

The mixing behavior of gas and liquid inside a static mixer was numerically investigated by using two-phase CFD simulations. The influence of the liquid superficial velocity is found to be significant. The mixing behavior at $J_{L}=0.2 \mathrm{~m} / \mathrm{s}$ is the worst since the swirling flow is not sustained at this velocity. Although the mixing behavior is largely improved by increasing the liquid superficial velocity, the unwanted gas layer near the upper part of the pipe still can be observed for $J_{L}<0.8 \mathrm{~m} / \mathrm{s}$. A welldistributed gas condition in the present study is achieving relatively high liquid superficial velocity (i.e., $J_{L}>0.8 \mathrm{~m} / \mathrm{s}$ ).

\section{References}

[1] B. Gjevik, H. Moe, and A. Ommundsen, "Sources of the Maelstrom," Nature, vol. 388, no. 6645, pp. 837838, Aug. 1997, DOI: 10.1038/42159.

[2] P. R. N. Childs, "Chapter 1 - Introduction to Rotating Flow," in Rotating Flow, P. R. N. Childs, Ed. Oxford: Butterworth-Heinemann, 2011, pp. 1-15.

[3] M. Sheikholeslami, M. Gorji-Bandpy, and D. D. Ganji, "Review of heat transfer enhancement methods: Focus on passive methods using swirl flow devices," Renew. Sustain. Energy Rev., vol. 49, pp. 444-469, Sep. 2015, DOI: 10.1016/j.rser.2015.04.113.

[4] O. Musa, C. Xiong, and Z. Changsheng, "Combustion characteristics and turbulence modeling of swirling reacting flow in solid fuel ramjet," Acta Astronaut., vol. 139, pp. 1-17, Oct. 2017, DOI: 10.1016/j.actaastro.2017.06.023.

[5] X. Luo, L. Yang, H. Yin, L. He, and Y. Lü, "A review of vortex tools toward liquid unloading for the oil and gas industry," Chem. Eng. Process. - Process Intensif., vol. 145, p. 107679, Nov. 2019, DOI: 10.1016/j.cep.2019.107679.

[6] S. Rabha, M. Schubert, F. Grugel, M. Banowski, and U. Hampel, "Visualization and quantitative analysis of dispersive mixing by a helical static mixer in upward co-current gas-liquid flow," Chem. Eng. J., vol. 262, pp. 527-540, Feb. 2015, DOI: 10.1016/j.cej.2014.09.019.

[7] R. A. Putra, M. Neumann-Kipping, T. Schäfer, and D. Lucas, "Comparison of Gas-Liquid Flow Characteristics in Geometrically Different Swirl Generating Devices," Energies, vol. 12, no. 24, 2019, DOI: $10.3390 /$ en 12244653.

[8] R. A. Putra, T. Schäfer, M. Neumann, and D. Lucas, "CFD studies on the gas-liquid flow in the swirl generating device," Nucl. Eng. Des., vol. 332, pp. 213-225, Jun. 2018, doi: 10.1016/j.nucengdes.2018.03.034.

[9] F. Zidouni, E. Krepper, R. Rzehak, S. Rabha, M. Schubert, and U. Hampel, "Simulation of gas-liquid flow in a helical static mixer," Chem. Eng. Sci., vol. 137, pp. 476-486, Dec. 2015, DOI: 10.1016/j.ces.2015.06.052.

[10] R. A. Putra, "Mixing Characteristics of Gas-Liquid Flow in a Static Mixer: A Numerical Study," Angkasa J. Ilm. Bid. Teknol., no. It is submitting in 2020.

[11] J. Yin, Y. Ma, Y. Qian, and D. Wang, "Experimental investigation of the bubble separation route for an axial gas-liquid separator for TMSR," Ann. Nucl. Energy, vol. 97, pp. 1-6, Nov. 2016, DOI: 10.1016/j.anucene.2016.06.018

[12] ANSYS, “ANSYS CFX-Solver Theory Guide, Release 19.2." 2019.

[13] F. R. Menter, "Two-equation eddy-viscosity turbulence models for engineering applications," AIAA J., vol. 32, no. 8, pp. 1598-1605, Aug. 1994, DOI: 10.2514/3.12149.

[14] Y. Sato and K. Sekoguchi, "Liquid velocity distribution in two-phase bubble flow," Int. J. Multiph. Flow, vol. 2, no. 1, pp. 79-95, Jun. 1975, DOI: 10.1016/0301-9322(75)90030-0.

[15] M. Ishii and N. Zuber, "Drag coefficient and relative velocity in a bubbly, droplet or particulate flow," AIChE J., vol. 25, no. 5, pp. 843-855, Sep. 1979, DOI: 10.1002/aic.690250513.

[16] A. Tomiyama, H. Tamai, I. Zun, and S. Hosokawa, "Transverse migration of single bubbles in simple shear flows," Chem. Eng. Sci., vol. 57, no. 11, pp. 1849-1858, Jun. 2002, DOI: 10.1016/S00092509(02)00085-4.

[17] S. P. Antal, R. T. Lahey, and J. E. Flaherty, "Analysis of phase distribution in fully developed laminar bubbly two-phase flow," Int. J. Multiph. Flow, vol. 17, no. 5, pp. 635-652, Sep. 1991, DOI: 10.1016/03019322(91)90029-3.

[18] A. D. Burns, T. Frank, I. Hamill, and J.-M. Shi, "The Favre Averaged Drag Model for Turbulent Dispersion in Eulerian Multi-Phase Flows," 5th Int. Conf. Multiph. Flow ICMF-2004 Yokohama Jpn., 2004.

[19] T. R. Auton, J. C. R. Hunt, and M. Prud'Homme, "The force exerted on a body in inviscid unsteady nonuniform rotational flow," J. Fluid Mech., vol. 197, pp. 241-257, 1988, doi: 10.1017/S0022112088003246. 
[20] J. Magnaudet, M. Rivero, and J. Fabre, "Accelerated flows past a rigid sphere or a spherical bubble. Part 1. Steady straining flow," J. Fluid Mech., vol. 284, pp. 97-135, 1995, DOI: 10.1017/S0022112095000280.

[21] M. R. Maxey and J. J. Riley, "Equation of motion for a small rigid sphere in a nonuniform flow," Phys. Fluids, vol. 26, no. 4, pp. 883-889, Apr. 1983, DOI: 10.1063/1.864230. 